\title{
Connexin 43-dependent tumor-suppressing effect of the Bowman-Birk protease inhibitor on M5076 ovarian sarcoma-bearing mice
}

\author{
NORITAKA SAKURAI ${ }^{1}$, KAZUYUKI SUZUKI ${ }^{1}$, TETSUYA NAGAOKA ${ }^{1}$, TERUYOSHI SAITO ${ }^{1}$, \\ HISASHI YOSHIMURA ${ }^{1}$, TOMOHIRO YANO ${ }^{2}$, YASUYUKI SADZUKA ${ }^{3}$ and RYUJI ASANO ${ }^{1}$ \\ ${ }^{1}$ Department of Veterinary Medicine, College of Bioresource Sciences, Nihon University, 1866 Kameino, \\ Fujisawa, Kanagawa 252-8510; ${ }^{2}$ Department of Food Science Research for Health, National Institute of \\ Health and Nutrition, 1-23-1 Toyama, Shinjuku, Tokyo 162-8636; ${ }^{3}$ School of Pharmacy, \\ Iwate Medical University, 2-2-1 Yahaba-cho, Shiwa-gunn, Iwate, 028-3694, Japan
}

Received April 11,2008; Accepted June 2, 2008

DOI: $10.3892 / \mathrm{mmr} 00000014$

\begin{abstract}
The present study was designed to confirm whether the Bowman-Birk inhibitor (BBI) induces an increase in p27 accumulation without $\mathrm{S}$ phase kinase-associated protein 2 (skp2) degradation by means of the expression of connexin (Cx) 43 as a gap junctional intercellular communication (GJIC)-dependent pathway in mice with M5076 ovarian sarcoma. M5076 ovarian sarcomas ( $1 \times 10^{5}$ cells/animal) were subcutaneously transplanted onto the backs of $\mathrm{BDF}_{1}$ mice receiving 10, 20 or $40 \mathrm{mg} / \mathrm{kg}$ of purified $\mathrm{BBI}$ intraperitoneally. Relative tumor weight $(\mathrm{p}<0.01, \mathrm{r}=0.503)$ was negatively correlated with the dose of BBI. In contrast, the relative density of Cx43 mRNA ( $<<0.01, r=0.570)$ and $\mathrm{Cx} 43$ ( $\mathrm{p}<0.01$, $\mathrm{r}=0.718$ ) was positively correlated with the dose of BBI, as were p21 $(\mathrm{p}<0.01, \mathrm{r}=0.633), \mathrm{p} 27(\mathrm{p}<0.01, \mathrm{r}=0.561)$ and skp2 $(\mathrm{p}<0.01, \mathrm{r}=0.733)$. We therefore suggest that the anticarcinogenic effects of BBI induce negative growth control by means of an increase in p27 accumulation caused by the expression of $\mathrm{Cx} 43$ as a GJIC pathway.
\end{abstract}

\section{Introduction}

The Bowman-Birk inhibitor (BBI) is a soybean-derived serine protease inhibitor with both trypsin and chymotrypsin inhibitory activites (1). BBI was identified by Bowman in 1946 (2) and later purified by Birk in 1961 (3). This molecule consists of an 8-kDa polypeptide (71 amino acids) and has two separate protease inhibitor sites: sub-domain $1\left(\mathrm{NH}_{2}-\right.$ terminal) and sub-domain 2 (COOH-terminal) for trypsin- and

Correspondence to: Dr Kazuyuki Suzuki, Department of Veterinary Medicine, College of Bioresource Sciences, Nihon University, 1866 Kameino, Fujisawa, Kanagawa 252-8510, Japan E-mail: kazuyuki@rakuno.ac.jp

Key words: Bowman-Birk inhibitor, connexin 43, M5076 ovarian sarcoma, p27, skp2 chymotrypsin-like serine proteases, respectively (4). Of the two sites, sub-domain 2 is the more important for chemoprevention, suggesting the importance of chymotrypsin inhibition in BBI chemopreventative activity (4-6). The anti-carcinogenic activity of BBI has been detected at nanomolar concentrations (7), and its ability to suppress carcinogenesis in animals exceeds that of the other potential chemopreventive agents identified in soybeans (8-10).

As cell-cell interaction structures, gap junctions (GJs) are membrane channels that permit the transfer of small watersoluble molecules $(\leq 1 \mathrm{kDa})$, including inositol triphosphate, from the cytoplasm of one cell to that of surrounding cells (11). This process is called gap junctional intercellular communication (GJIC), and plays an important role in the maintenance of homeostatic control in multi-cellular organisms for the regulation of cell proliferation, differentiation, apoptosis, wound-healing and the adaptive responses of differentiated cells $(12,13)$. Most tumor cells have a reduced ability to communicate between themselves and/or with surrounding normal cells, confirming the importance of functional GJIC in growth control (11). Therefore, the inhibition of GJIC between adjacent cells has been postulated to be one of the important events occurring during the promotional stage of cancer $(14,15)$. GJs are composed of proteins known as connexins (Cxs), which consist of a multigene family of highly related proteins with molecular weights between 26 and $70 \mathrm{kDa}$. More recently, direct evidence of the role of GJIC in tumor suppression has been obtained by transfecting $\mathrm{Cx}$ genes into non-communicating tumor cells (14,16-19). On the other hand, there is increasing evidence of GJIC-independent roles for Cxs in the control of cell growth and the suppression of carcinogenicity (20). Based on these reports, Cxs are considered to act as tumor suppressor genes in a GJIC-dependent and -independent manner.

A previous study of ours demonstrated that the anticarcinogenic effects of BBI induced negative growth caused by the restoration of the expression of Cx43 genes in M5076 ovarian sarcoma-bearing mice (21). Zhang et al (22) reported that $\mathrm{Cx} 43$ suppresses the G1-S phase of cell cycle transition by increasing p27 levels. It has recently been reported that a 
novel route by which $\mathrm{Cx} 43$ inhibits cell proliferation is the suppressed expression of $\mathrm{S}$ phase kinase-associated protein 2 (skp2), the human F-box protein that regulates p27 ubiquitination via a GJIC-independent pathway $(13,22,23)$. The present study was therefore designed to confirm whether BBI induces increases in p27 accumulation without skp2 degradation due to the expression of $\mathrm{Cx} 43$ as a GJIC-dependent pathway.

\section{Materials and methods}

Chemicals and antibodies. Purified BBI (>99\% pure) was obtained from Dr K. Takamatsu (Fujioil Co., Osaka, Japan). Primary antibodies to mouse Cx43 (Chemicon International Inc., Temecula, CA, USA), mouse p21 (Upstate Cell Signaling Technology, NY, USA), mouse p27 (BD Sciences, Tokyo, Japan), mouse skp2 (Zymed Laboratories Inc., CA, USA), and mouse B-actin (Sigma-Aldrich Co., St. Louis, MO, USA), and all the respective secondary anti-mouse IgGconjugated antibodies (Beckman Coulter Co., Cedex, France), were purchased from the companies indicated. M5076 ovarian sarcoma cells were kindly provided by Dr T. Tashiro (Japanese Foundation for Cancer Research, Tokyo, Japan).

Animals. Male C57BL/6 and $\mathrm{BDF}_{1}\left(\mathrm{~F}_{1}\right.$ from C57BL/6 female and DBA/2 male) mice, 5 weeks of age and 20-25 g in weight, were obtained from Clea Japan Inc. (Tokyo, Japan) and housed in a room maintained at $22 \pm 1{ }^{\circ} \mathrm{C}$ and $55.5 \%$ relative humidity. The mice were kept in groups of four per cage and given free access to regular chow pellets (CE-2, Clea Japan Inc.) and fresh water. They were acclimatized for 1 week prior to use, and kept throughout under standard conditions.

In vivo tumor experiment. C57BL/6 mice were used for the animal passage of M5076 cells, and $\mathrm{BDF}_{1}$ mice were used for in vivo experiments. For animal passage, M5076 ovarian sarcomas $\left(1 \times 10^{6}\right.$ cells/animal $)$ were transplanted intraperitoneally (i.p.) into C57BL/6 mice. Ascitic cells were collected on the 14th day after transplantation (24).

M5076 ovarian sarcomas $\left(1 \times 10^{5}\right.$ cells/animal $)$ were subcutaneously transplanted onto the backs of $\mathrm{BDF}_{1}$ mice. After 15 days, the mice were randomly assigned to the control (injection of sterile saline), low (10 mg BBI $/ \mathrm{kg}$ ), middle (20 mg BBI/ $\mathrm{kg}$ ), or high (40 mg BBI/ $\mathrm{kg}$ ) dosage groups. Each treatment group comprised 7 animals. Purified BBI was intraperitoneally injected on day 15, 18, 20, 22, 25, 27, 29,32 and 34 after transplantation. The mice were sacrificed on the 35th day after inoculation by cervical dislocation, and the solid tumors were immediately removed and weighed.

Real-time polymerase chain reaction analysis. Total RNA was extracted with a lysis reagent (Qiazol, Qiagen Inc., Valencia, CA, USA) according to the manufacturer's instructions, and the RNA extract was stored at $-80^{\circ} \mathrm{C}$ until use. Glyceraldehyde-3phosphate dehydrogenase (GAPDH) was used as an internal control. The following primers (each at a final concentration of $1 \mathrm{pM}$ ) were used: for $\mathrm{Cx} 43$ (Accession no. NM 010288), 5'-CTT GAA CAT CAA GCT GCC AATC-3' and 5'-TCC ACG GGA ACG AAA TGA AC-3'; for GAPDH (Accession no. BC 083149), 5'-TGC ACC ACC AAC TGC TTA GC-3'

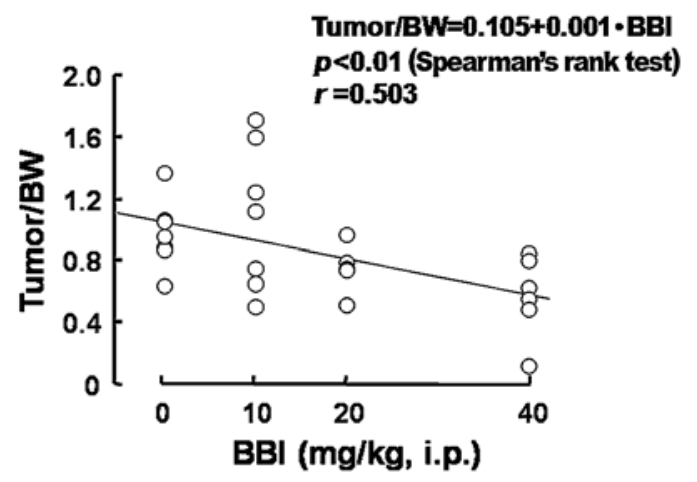

Figure 1. Relationship between Bowman-Birk inhibitor (BBI) dosage and tumor/body weight (BW) ratio in M5076-bearing mice.

and 5'-TGG CAG TGA TGG CAT GGA-3'. All primer pairs were designed to encompass at least one intron of the genomic sequence to allow for the discrimination of any sequences amplified from contaminating genomic DNA. Additionally, all were synthesized by Operon Biotechnologies, Inc. (Huntsville, AL, USA) and were of HPSF quality.

Aliquots of the cDNAs were incubated with Takara Premix Taq (Takara Bio Inc., Tokyo, Japan). The polymerase was activated $\left(1 \mathrm{~min}\right.$ at $\left.95^{\circ} \mathrm{C}\right)$ and then up to 40 cycles $(5 \mathrm{sec}$ at $95^{\circ} \mathrm{C}, 1 \mathrm{~min}$ at $60^{\circ} \mathrm{C}$ ) were performed on an iCycler (Bio-Rad Laboratories Inc., Hercules, CA, USA). Real-time PCR was conducted with an Applied Biosystem TaqMan 7500 (Applera GmbH, Germany) in 96-well plates using SYBR ${ }^{\circledR}$-Premix ExTaq (Applera GmbH) in $25 \mu 1$ reaction mixtures. Results were analyzed by absolute quantification (standard curve) using the ABI PRISM 7500 Sequence Detection System V1.2.3 (Applera $\mathrm{GmbH}$ ).

Western blot analysis. Tumor tissues were minced and homogenized with a homogenizer in ice-cold lysis buffer. Supernatants were collected and used to examine the expression of different proteins by Western blotting. Protein concentrations were determined by the Bradford method (Biowave S2100, Funakoshi Co., Tokyo, Japan).

Total protein extract $(20 \mu \mathrm{g})$ from the tumors of mice treated with various doses of BBI was loaded onto $10 \%$ SDSpolyacrylamide gel for analysis of the expression of $\mathrm{Cx} 43$, p21, p27 and skp2. ß-actin was used as an internal standard. After electrophoresis, the proteins were transferred onto nitrocellulose membranes. Protein expression levels were detected using enhanced chemiluminescence detection systems (ChemDoc, Bio-Rad Laboratories, Tokyo, Japan). The relative density of each protein band on a blot was measured using computer software Quantity One Version 4.5 (Bio-Rad). Molecular sizing was conducted using the Rainbow MW marker (Amersham Health, Buckinghamshire, UK).

Statistical analysis. Data were expressed as the means \pm standard deviation. The relationship between the doses of BBI and each parameter was evaluated by Spearman's rank test. To test changes in relation to $\mathrm{BBI}$, data for each group were analyzed by repeated-measures ANOVA followed by the Bonferroni test. The level of significance was determined to be $\mathrm{p}<0.05$. 
Table I. Relationship between Bowman-Birk inhibitor dosage and study parameters.

\begin{tabular}{llcrr}
\hline & Control & \multicolumn{3}{c}{ Bowman-Birk inhibitor } \\
\cline { 4 - 5 } & & $10 \mathrm{mg} / \mathrm{kg}$ & $20 \mathrm{mg} / \mathrm{kg}$ & $40 \mathrm{mg} / \mathrm{kg}$ \\
\hline Cx43 mRNA (density/GAPDH) & $0.509 \pm 0.062$ & $0.572 \pm 0.152$ & $0.675 \pm 0.127$ & $0.970 \pm 0.160^{\mathrm{a}}$ \\
Cx43 (density/B-actin) & $0.667 \pm 0.076$ & $0.990 \pm 0.238^{\mathrm{a}}$ & $1.091 \pm 0.209^{\mathrm{a}}$ & $1.259 \pm 0.214^{\mathrm{a}}$ \\
p21 (density/B-actin) & $0.675 \pm 0.089$ & $0.925 \pm 0.247$ & $1.194 \pm 0.247^{\mathrm{a}}$ & $1.212 \pm 0.289^{\mathrm{a}}$ \\
p27 (density/B-actin) & $0.717 \pm 0.173$ & $0.939 \pm 0.223$ & $1.199 \pm 0.273^{\mathrm{a}}$ & $1.168 \pm 0.261^{\mathrm{a}}$ \\
skp2 (density/ß-actin) & $0.625 \pm 0.109$ & $0.874 \pm 0.249$ & $1.167 \pm 0.290^{\mathrm{a}}$ & $1.358 \pm 0.334^{\mathrm{a}, \mathrm{b}}$ \\
\hline
\end{tabular}

${ }^{\mathrm{a}} \mathrm{p}<0.05$ versus control; ${ }^{\mathrm{b}} \mathrm{p}<0.05$ versus $10 \mathrm{mg} / \mathrm{kg}$ (Bonferroni test) $(\mathrm{p}<0.0083)$.

A

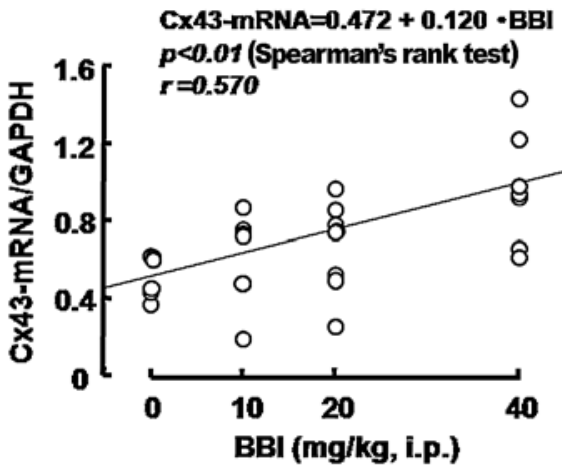

B

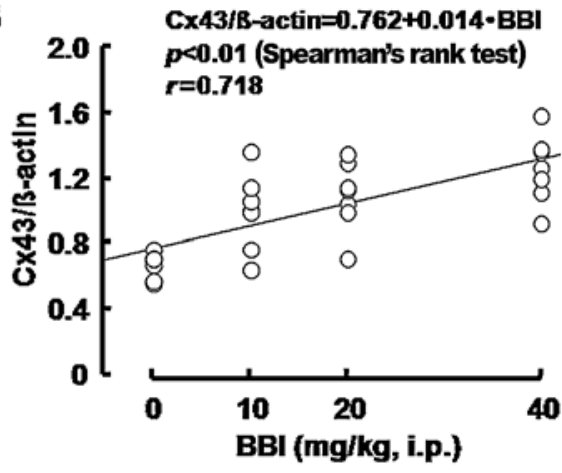

Figure 2. Relationship between Bowman-Birk inhibitor (BBI) dosage and connexin 43 levels in M5076-bearing mice. (A) Real-time PCR analysis of Cx43 mRNA expression and (B) Western blot analysis of Cx43 density per ß-actin in M5076-bearing mice.

\section{Results}

Fig. 1 shows the relationship between BBI dosage and relative tumor weight (tumor/body weight) in M5076 ovarian sarcomabearing mice. Relative tumor weight was negatively correlated with the dose of BBI $(\mathrm{p}<0.01, \mathrm{r}=0.503)$. High doses of BBI significantly reduced relative tumor weight by $34.0 \%$ compared to control levels $(\mathrm{p}<0.05)$.

The relative densities of Cx43 mRNA per GAPDH mRNA and $\mathrm{Cx} 43, \mathrm{p} 21, \mathrm{p} 27$ and skp2 per $\beta$-actin are summarized in Table I. Fig. 2 shows the relationship between BBI dosage and the relative density of $\mathrm{Cx} 43$ mRNA (Cx43 mRNA/GAPDH mRNA) and Cx43 (Cx43/ß-actin) in M5076 ovarian sarcomabearing mice. The relative density of $\mathrm{Cx} 43 \mathrm{mRNA}(\mathrm{p}<0.01$, $\mathrm{r}=0.570)$ and $\mathrm{Cx} 43(\mathrm{p}<0.01, \mathrm{r}=0.718)$ was positively correlated with the dose of BBI. The relative density of $\mathrm{Cx} 43$ mRNA in mice that received $40 \mathrm{mg} / \mathrm{kg}$ BBI $(0.970 \pm 0.128)$ was significantly higher than in the control mice $(0.509 \pm 0.076$, $\mathrm{p}<0.05)$. In addition, the relative density of $\mathrm{Cx} 43$ in mice that received $10 \mathrm{mg} / \mathrm{kg}(0.990 \pm 0.238), 20 \mathrm{mg} / \mathrm{kg}(1.091 \pm 0.209)$, and $40 \mathrm{mg} / \mathrm{kg}$ BBI $(1.259 \pm 0.214)$ was significantly higher than in the control mice $(0.667 \pm 0.076, \mathrm{p}<0.05)$.

Fig. 3 shows the relationship between BBI dosage and the relative densities of proteins, including p21, p27 and skp2, in M5076 ovarian sarcoma-bearing mice. The relative densities of p21 ( $\mathrm{p}<0.01, \mathrm{r}=0.633), \mathrm{p} 27(\mathrm{p}<0.01, \mathrm{r}=0.561)$ and $\mathrm{skp} 2$ $(\mathrm{p}<0.01, \mathrm{r}=0.733)$ were positively correlated with the dose of BBI. At 20 and $40 \mathrm{mg} / \mathrm{kg}$, BBI significantly increased the relative densities of $\mathrm{p} 21, \mathrm{p} 27$ and $\mathrm{skp} 2$ compared to control levels $(\mathrm{p}<0.05$, respectively).

\section{Discussion}

The present study demonstrates that BBI induces increases in p27 accumulation without skp2 degradation through the expression of $\mathrm{Cx} 43$ as a GJIC-dependent pathway. This suggests that the anti-carcinogenic effects of BBI induced negative growth control due to an increase in p27 accumulation caused by the expression of $\mathrm{Cx} 43$ as a GJIC-dependent pathway.

Epidemiological evidence indicates that diets containing high amounts of soybean products are associated with a lower incidence of cancer and lower mortality rates $(25,26)$. In an effort to explain this phenomenon, epidemiologists have proposed various hypotheses, including differences in diet and environmental exposure to carcinogens $(25,26)$. Dietary comparisons of the Asian with a typical Western diet reveal many differences, among them the fact that Asian populations, in particular those of China and Japan, consume more soybean products than those of Western countries. Consequently, several of the components of soybeans have been isolated and investigated as cancer preventive agents (27). BBI is a soybean-derived serine protease inhibitor with both trypsin and chymotrypsin inhibitory activities (1). This polypeptide has been shown to be a very potent 'pure' chemopreventive agent, and is the only protease inhibitor from soybeans which possesses isolated chymotrypsin inhibition activity (27). 
A
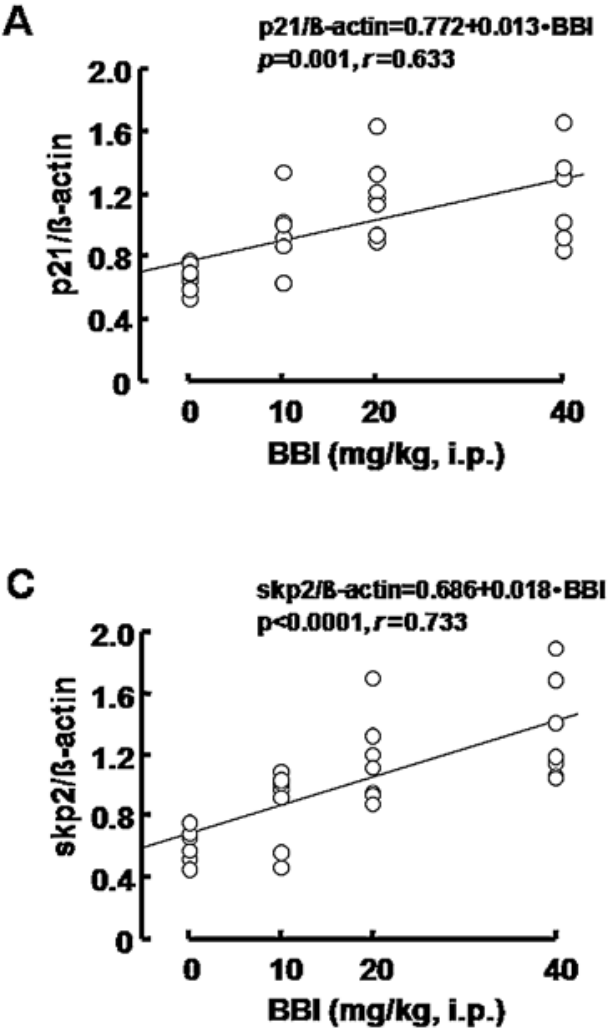

Figure 3. Effects of Bowman-Birk inhibitor (BBI) treatment on p21, p27 and skp2 expression levels per $B$-actin in M5076-bearing mice.

This study demonstrates that Cx43 mRNA and Cx43 protein levels are positively correlated with BBI dosage. Zhang et al $(13,22,23)$ suggested that $\mathrm{Cx}$ genes inhibit tumor cell growth, most probably via two pathways. One is linked to the Cx-mediated GJIC function, in which putative growth inhibitory factors are assumed to diffuse through GJ channels and subsequently to induce growth inhibition, while in the other it is likely that $\mathrm{Cx}$ proteins themselves play GJICindependent biological roles in inhibiting tumor cell growth (23). Enforced Cx43 expression markedly increased p27 levels and inhibited the activities of cyclin-dependent kinases 2 and 4. Thus, we confirmed that the anti-carcinogenic effect of BBI induced negative growth control by means of the accumulation of p27 in mice bearing M5076 ovarian sarcoma. This accumulation was the result of the increased synthesis and reduced degradation of $\mathrm{p} 27$ proteins. The $\mathrm{N}$-terminal domain of $\mathrm{Cx} 43$, which forms the GJ, is sufficient for the promotion of the synthesis of p27 protein, in which cyclic AMP is involved $(23,24)$. In contrast, the C-terminal domain of $\mathrm{Cx} 43$, which does not form a GJ, was sufficient for the inhibition of the expression of skp2. Although the down-regulation of skp2 was responsible for the increase in the levels of $\mathrm{p} 27$ protein by the GJIC-independent pathway, we did not observe a downregulation of skp2 expression in mice bearing M5076 ovarian sarcoma. In this study, BBI induced an increase in skp2 levels, an effect which was strongly dose-dependent. This increase might be an attempt at compensating for the increase in p27, rather than a direct action of BBI. These findings reveal a GJIC-dependent pathway through which Cx43 inhibits tumor growth by causing an increase in the synthesis of $\mathrm{p} 27$ protein. We suggest that the GJIC-dependent pathway contributed

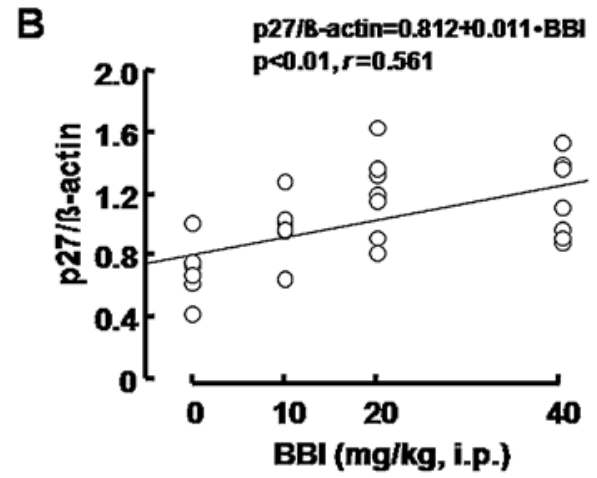

much more to the inhibition of $\mathrm{Cx} 43$-induced tumor proliferation in mice bearing the M5076 ovarian sarcoma than did the GJIC-independent pathway.

The effects of the induction of Cx43 mRNA synthesis and the inhibition of $\mathrm{Cx} 43$ protein degradation contribute to the stabilization of GJs and to the reinforcement of the tumorsuppressive effect of $\mathrm{Cx} 43$ based on their formation (28). Thus, the effect of BBI on Cx43 may aid in the establishment of potential cancer chemoprevention and therapy based on $\mathrm{Cx}$ functions. BBI could therefore be a potential agent for cancer chemoprevention and therapy, as it stimulated the biosynthesis of $\mathrm{Cx} 43$ and suppressed the degradation of the $\mathrm{Cx} 43$ protein $(29,30)$. Destruction of the Cx43 protein mainly depends on the ubiquitin-proteasome system $(29,30)$, and chymotrypsinlike activity involved in the proteasome is specifically required for its degradation $(30,31)$.

In conclusion, the present study suggests that the anticarcinogenic effects of $\mathrm{BBI}$ are due to the induction of negative growth control by means of an increase in p27 accumulation caused by the restoration of the expression of $\mathrm{Cx} 43$ as a GJIC pathway, an effect which was strongly dose-dependent.

\section{Acknowledgements}

This study was supported by a research grant from the Fuji Foundation for Protein Research, a research grant on Health Science Focusing on Drug Innovation from the Japan Human Sciences Foundation (KH21012), a Grant-in-Aid for Science Research from the Ministry of Education, Culture and Sciences of Japan (no. 16580259) to T.Y., and a Nihon University Research Grant for researchers to K.S.

\section{References}

1. Birk Y: The Bowman-Birk protease inhibitor: trypsin- and chymotrypsin- inhibitor from soybeans. Int J Pept Protein Res 25: 113-131, 1985.

2. Bowman DE: Differentiation of soybean antitryptic factors. Proc Soc Exp Biol Med 63: 547-550, 1946.

3. Birk Y: Purification and some properties of a highly active inhibitor of trypsin and alpha-chymotrypsin from soybeans. Biochim Biophys Acta 54: 191-197, 1961.

4. Lippman SM and Matrisian LM: Protease inhibitors in oral carcinogenesis and chemoprevention: Clin Cancer Res 6: 4599-4603. 2000.

5. Kennedy AR: The Bowman-Birk inhibitor from soybeans as an anticarcinogenic agent. Am J Clin Nutr 68 (Suppl 6): 1406-1412, 1998.

6. Kennedy AR: Chemopreventive agents; protease inhibitors. Pharmacol Ther 78: 167-209, 1998. 
7. Yavelow J, Collins M, Birk Y, Troll W and Kennedy AR: Nanomolar concentrations of Bowman-Birk soybean protease inhibitor suppress X-ray induced transformation in vitro. Proc Natl Acad Sci USA 82: 5395-5399, 1985.

8. Armstrong WB, Kennedy AR, Wan XS, Atiba J, McLaren CE and Meyskens FL: Single-dose administration of Bowman-Birk inhibitor concentrate in patients with oral leukoplakia. Cancer Epidemiol Biomarkers Prev 9: 43-47, 2000.

9. Armstrong WB, Kennedy AR, Wan XS, et al: Clinical modulation of oral leukoplakia and protease activity by Bowman-Birk inhibitor concentrate in a phase IIa chemoprevention trial. Clin Cancer Res 6: 4684-4691, 2000.

10. St. Clair WH, Billings PC and Kennedy AR: The effects of the Bowman-Birk protease inhibitor on c-myc expression and cell proliferation in the unirradiated and irradiated mouse colon. Cancer Lett 52: 145-152, 1990.

11. Kang KS, Kang BC, Lee BJ, et al: Preventive effect of epicatechin and ginsenoside $\mathrm{Rb}_{2}$ on the inhibition of gap junctional intercellular communication by TPA and $\mathrm{H}_{2} \mathrm{O}_{2}$. Cancer Lett 152: 97-106, 2000.

12. Nishimura M, Saito T, Yamasaki H and Kudo R: Suppresion of gap junctional intercellular communication via $5^{\prime} \mathrm{CpG}$ island methylation in promoter region of E-cadherin gene in endometrial cancer cells. Carcinogenesis 24: 1615-1623, 2003.

13. Zhang YW, Kaneda M and Morita I: The gap junction-independent tumor-suppressing effect of connexin 43. J Biol Chem 278: 44852-44856, 2003.

14. Fujimoto E, Satoh H, Negishi E, et al: Negative growth control of renal cell carcinoma cell by connexin 32: possible involvement of Her-2. Mol Carcinog 40: 135-142, 2004.

15. Loewenstein WR and Kanno Y: Intercellular communication and the control of tissue growth: lack of communication between cancer cells. Nature 209: 1248-1249, 1966.

16. Berke G, Krutovskikh V and Yamasaki H. Connexin 37 gene is not mutated in lung carcinomas 3LL and CMT. Cancer Lett 195: 67-72, 2003.

17. Hirai A, Yano T, Nishikawa K, et al: Down-regulation of connexin 32 gene expression through DNA methylation in a human renal cell carcinoma cell. Am J Nephrol 23: 172-177, 2003.

18. Yano T, Hernandez-Blazquez F, Omori Y and Yamasaki H: Reduction of malignant phenotype of HEPG2 cell is associated with the expression of connexin 26 but not connexin 32 . Carcinogenesis 22: 1593-1600, 2001.
19. Yano T, Ito F, Kobayashi K, et al: Hypermethylation of the GpG island of connexin 32, a candidate tumor suppressor gene in renal cell carcinomas from hemodialysis patients. Cancer Lett 208: 137-142, 2004.

20. Jiang JX and Gu S: Gap junction- and hemichannel-independent actions of connexins. Biochim Biophys Acta 1711: 208-214, 2005.

21. Suzuki K, Yano T, Saduzka Y, Sugiyama T, Seki T and Asano R: Restoration of connexin 43 by Bowman-Birk protease inhibitor in M5076-bearing mice. Oncol Rep 13: 1247-1250, 2005.

22. Zhang YW, Nakayama K, Nakayama K and Morita I: A novel route for connexin 43 to inhibit cell proliferation: negative regulation of s-phase kinase-associated protein (skp2). Cancer Res 63: 1623-1630. 2003.

23. Zhang YW, Morita I, Ikeda M, Ma KW and Murota S: Connexin43 suppresses proliferation of osteosarcoma U2OS cells through post-transcriptional regulation of p27. Oncogene 20 : 4138-4149, 2001

24. Sugiyama T and Sadzuka Y: Combination of theanine with doxorubicin inhibits hepatic metastasis of M5076 ovarian sarcoma. Clin Cancer Res 5: 413-416, 1999.

25. Wu AH, Wan P, Hankin J, Tseng CC, Yu MC and Pike MC: Adolescent and adult soy intake and risk of breast cancer in Asian-Americans. Carcinogenesis 23: 1491-1496, 2002.

26. Wu AH, Ziegler RG, Nomura AM, et al: Soy intake and risk of breast cancer in Asians and Asian Americans. Am J Clin Nutr 68 (Suppl 6): 1437-1443, 1998.

27. Du X, Beloussow K and Shen WC: Bowman-Brink protease inhibitor and its palmitic acid conjugate prevent 7,12-dimethylbenz $[a]$ anthracene-induced transformation in cultured mouse mammary gland. Cancer Lett 164: 135-141, 2001.

28. Salameh A and Dhein S: Pharmacology of gap junctions. New pharmacological targets for treatment of arrhythmia, seizure and cancer? Biochim Biophys Acta 1719: 36-58, 2005.

29. Segretain D and Falk MM: Regulation of connexin biosynthesis, assembly, gap junction formation, and removal. Biochim Biophys Acta 1662: 3-21, 2004.

30. Saito T, Sato H, Virgona N, et al: Negative growth control of osteosarcoma cell by Bowman-Birk protease inhibitor from soybean; involvement of connexin 43. Cancer Lett 253: 249-257, 2007.

31. Leithe E and Riverdal E: Epidermal growth factor regulates ubiquitination, internalization and proteasome-dependent degradation of connexin 43. J Cell Sci 117: 1200-1211, 2004. 